\title{
Medical hegemony
}

Volume 3 Issue 2 - 2016

\section{Medicalization}

Hegemony is defined as the preponderant influence or authority over others, the social, cultural, ideological, or economic influence exerted by a dominant group. Medical hegemony is the dominance of the biomedical model, the active suppression of alternatives as well as the corporatization of personal, clinical medicine into pharmaceutical and hospital centered treatment. ${ }^{1}$

Biomedicine has fostered a process social scientists refer to as medicalization. This process entails the absorption of ever-widening social arenas and behaviors into the jurisdiction of biomedical treatment. ${ }^{1}$ Medical hegemony underlies the medicalization of contemporary life. Cultural assumptions and values, and what is considered disease come to permeate medical diagnosis and treatment. ${ }^{2}$ Medical Nemesis, first published in 1975 and written by Ivan Illich ${ }^{3}$ attacked the medicalization of daily life. He argued that the medicalization of normal, daily human experiences; birth and death, sadness and grief frequently causes more harm than good and turned people into lifelong patients. He suggested medicine creates a need for remedies that simply treat normal human responses. He also questioned the profit motive in medical science.

When medicine became an economic commodity and the for-profit medical care industry dominates research and health care delivery it created an immense influence from a powerful lobby, which is the necessary conditions for the maintenance of hegemony. Money and political power underlie the continuing the hegemonic structure, which through the co-option of the economic reality, and political power, dictate how medicine is defined. The political and economic power of hegemonic medicine ensures that it and it alone define what the right is and correct process of treatment for what that medicines determines to be sickness. ${ }^{4}$

The physician-patient interaction is unequal and a social relationship based on a power imbalance. Physicians dictate the rules of this relationship through exclusivity of information, status and money. The patients are expected to comply without questioning the medical authority. Submitting to the hegemony of the physician and passively and uncritically absorbing and then agreeing to this power imbalance reinforces the hegemony. The reproduction of this part of the hegemonic structure is absolutely essential for the continuation of the hegemonic structure. Fear, insecurity and lack of adequate knowledge cannot be resolved without the removal of the micro level interaction based on power. ${ }^{5-7}$ Medical hegemony positions itself beyond criticism and reproach from non-doctors and creates an elitism that does not serve the individual patient. ${ }^{8}$

The hegemonic alliance ${ }^{9}$ is the dominant economic force and is comprised of political society, medical universities, medical societies and the pharmaceutical industry. This ideological superstructure has been maintained, strengthened and reproduced through political and economic interests that, are linked by a common interest. Medicalization is now more driven by commercial and market interests than by professional claims-makers. ${ }^{10}$

\section{Daniel Weber \\ Tianjin University, China}

Correspondence: Daniel Weber,Visiting professor, Tianjin University, China, Email drdweber@panaxea.com

Received: January 08, 2016 | Published: February 9, 2016
Biomedicine, taking a scientific approach in looking at efficacy, demands an "efficacy" with standardized and systematic scientific protocols. Despite the methodological incompatibility with alternative medicine's underlying philosophy and the nature of its practice, biomedical "efficacy" has achieved its dominance. ${ }^{11}$ The issue however, is not efficacy itself but how one arrives at the evidence of efficacy. The use of narrow and restrictive research methodology at the expense of whole systems analysis creates an elite criterion that requires extraordinary resources to arrive at seemingly simple solutions. Expensive research that only benefits the elite that control that research.

There is beginning to emerge a distance between hegemonic biomedicine and the lay populace, the consumer, the suffering patient is beginning to liberate him or herself from the dominant medical paradigm and electing to search out other approaches to health care. ${ }^{12}$

\section{Medical pluralism}

Medical pluralism is the employment of more than one medical system or the use of both biomedicine and complementary and alternative medicine (CAM) approaches..$^{13}$ One in 3 adults in the United States uses CAM. ${ }^{14}$ In 2008 approximately 38 per cent of adults (about 4 in 10) and approximately 12 per cent of children (about 1 in 9) are using some form of CAM. CAM use among adults is greater among women and those with higher levels of education and higher incomes. ${ }^{15}$ The reason for this trend toward the use of CAM therapies is largely dissatisfaction with the biomedical health paradigm, which is perceived as elitist, condescending, overly focused on pathology and expensive. ${ }^{16}$ CAM therapies are often seen as less authoritarian and more congruent with patient's values, reflecting a more equal relationship. This relationship focuses on the meaning of health and not the treatment of disease. ${ }^{17}$

The future of an integrated medical system often depends on the societal history and their political, economic and social pressures. Some countries like the United Kingdom that has had a long history social medicine and has embraced a variety of CAM procedures. ${ }^{18}$ Canada and Australia also has social medicine but does not embrace CAM procedures. In the US, various HMO will or will not support CAM therapies, depending on the market forces. ${ }^{19}$

Integrative medicine is described as more than just the sum of conventional medicine plus CAM, it is about a dialogue between various experts in differing medical disciplines and includes the patient himself or herself. Integrative medicine is "healing-oriented medicine that reemphasizes the relationship between patient and 
physician, and integrates the best of complementary and alternative medicine with the best of conventional medicine". ${ }^{20}$ Keith Berndtson ${ }^{21}$ says "integrative medicine refers to a clinical approach that combines the strengths of conventional and alternative medicine with a bias toward options that are considered safe, and which, upon review of the available evidence, offer a reasonable expectation of benefit to the patient."

\section{Summary}

The professional medicine of Western cultures is called biomedicine, allopathic medicine or simply medicine, and has become the dominant form of medical invention. But biomedicine, like the medicine of other cultures, is influenced by conditions and beliefs in the culture, and therefore reflects the value and norms of its creators. Biomedicine purports to be objective and independent of bias, however the very concept of science is not to find out what is true but to discover what is not. Science is socially constructed and its beliefs and practices may partly derive from assumptions and biases in the culture. Real science seeks not to find 'truth' but find the best possible answer to problems that exist. The best possible answer until a better answer comes forth. ${ }^{22}$

Medical science under the influence of its hegemonic masters is not serving science itself but entrenching its dominance and power and creating powerful elite that suppresses real scientific discovery. No one denies the efficacy of scientific medicine but it has all the limitations of any system that denies its limitations and crushes alternative systems.

The future lies in creating a dialogue, which brings all valid approaches to medical science together and fosters critical dialogue to advance clinical therapies, whatever their focus.

\section{Acknowledgments}

None.

\section{Conflicts of interest}

Author declares there are no conflicts of interest.

\section{Funding}

None.

\section{References}

1. Baer HA, Singer M, Susser I. Medical Anthropology and the World System. 2nd edn. Praeger, CA, USA. 2004. p. 14.

2. Baer HA, Singer, M, Susser I. Medical Anthropology and the World System: A Critical Perspective. Bergin and Garvey, Westport, CT, USA. 1997.

3. Illich I. Limits to Medicine: Medical Nemesis, the Expropriation of Health. Reprint edition, Marion Boyars Publishers Ltd, London, UK. 2000 .
4. Shariati MS.Hegemony and the U.S. Health Care Crisis: Structural Determinants and Obstacles to a National Health Insurance Program. Payv and Iran News. 2010.

5. Parsons T. The Structure of Social Action. 2nd edn. Volume 1, Free Press. 1967.

6. Parsons T. The Structure of Social Action. 2nd edn. Volume 2, Free Press. 1967.

7. Parsons T. The Social System. Quid Pro LLC, Louisiana, USA. 2012.

8. Jorm C. Reconstructing Medical Practice: Engagement, Professionalism and Critical Relationships in Health Care. 1st edn. USA: Gower Pub Co; 2012. p.7.

9. Gramsci A. Selection From The Prison Notebooks. From Essential Classics in Politics: Antonio Gramsci. ElecBook, London, UK. 1999.

10. Conrad P. The Shifting Engines of Medicalization. Journal of Health and Social Behavior. 2005;46(1):13-14.

11. Efficacy of Alternative Medicine: Biomedical Hegemony.

12. Williams SJ, Calnan M. The 'limits' of medicalization?: Modern medicine and the lay populace in 'late' modernity. Social Science \& Medicine. 1996;42(12):1609-1620.

13. Wade C, Chao M, Kronenberg F, et al. Medical Pluralism among American Women: Results of a National Survey. J Womens Health (Larchmt) . 2008;17(5):829-840.

14. Eisenberg DM, Kessler RC, Foster C, et al. Unconventional medicine in the United States: prevalence, costs, and pattserns of use. $N$ Engl J Med. 1993;328(4):246-252.

15. https://nccih.nih.gov/research/statistics/2007/camsurvey_fs 1 . htm?lang $=\mathrm{es} \% 202008$

16. Fox E. Predominance of the curative model of medical care: A residual problem. JAMA. 1997;278(9):761-763.

17. Astin JA. Why patients use alternative medicine: results of a national study. JAMA. 1998;279(19):1548-1553.

18. Coates JR, Jobst KA. Integrated Healthcare: A Way Forward for the Next Five Years? A Discussion Document from the Prince of Wales Initiative on Integrated Medicine. J Alt Complement Med. 1998;4(2):209-247.

19. Kelner M, Wellman B. The Future of CAM. In: Kelner M, Wellman B, Editors. Complementary and Alternative Medicine: Challenge and Change. 1st edn. UK: Routledge, London; 2014. p. 209.

20. Maizes V, Schneider C, Bell I, et al. Integrative medical education: Development and implementation of a comprehensive curriculum at the University of Arizona. Acad Med. 2002;77(9): 851-860.

21. Berndtson K. Complementary and alternative medicine. Integrative medicine: Business risks and opportunities. Physician Exec. 1998;24(6):22-25.

22. Breedlove C, Hedrick H. Research in medical education: 1998 call for papers. JAMA. 1997;278(20):1702-1703. 